\title{
Directive Microstrip Antennas for Specific Below -2.45 GHz Applications
}

\author{
E. Ávila-Navarro ${ }^{1}$ and C. Reig ${ }^{2}$ \\ ${ }^{1}$ Área de Tecnología Electrónica, Universidad Miguel Hernández, Avenida Universidad s/n, 03202 Elche, Spain \\ ${ }^{2}$ Department of Electronic Engineering, Universitat de València, Avenida Dr. Moliner 50, 46100 Burjassot, Spain \\ Correspondence should be addressed to E. Ávila-Navarro, eavila@umh.es
}

Received 29 November 2011; Accepted 29 January 2012

Academic Editor: Deb Chatterjee

Copyright ( 2012 E. Ávila-Navarro and C. Reig. This is an open access article distributed under the Creative Commons Attribution License, which permits unrestricted use, distribution, and reproduction in any medium, provided the original work is properly cited.

\begin{abstract}
Microstrip printed antennas are the preferred choice in high data ratio modern communications, mainly at $2.45 \mathrm{GHz}$ and above. In this paper, we propose two different approaches of microstrip printed antennas for lower frequency usage. In this sense, we present a printed microstrip Yagi-like antenna at $868 \mathrm{MHz}$ and a printed dipole log-periodic antenna for wider band applications. We focus on the use of low-cost substrates, with a good performance at these frequencies, and giving antennas with useful sizes for such applications. For the analysis, we make use of standard experimental characterization combined with full-wave 3D-FDTD specifically developed simulations. In this way, the $S_{11}$, radiation patterns, and gain/efficiency figures are given.
\end{abstract}

\section{Introduction}

Nowadays, printed antennas are widely used for common mobile communication applications. Every cellular gadget includes one or more integrated antenna in order to match the specifications of the different communication protocols, the most of them under the $802.11 x$ umbrella. In fact, typical GSM and related communication channels are progressively moving to higher frequency layers. Driven by these technological requirements, research on compact antennas is mainly focusing on small omnidirectional antennas for $2.45 \mathrm{GHz}$, and above [1].

Nevertheless, even though printed technology is not restricted to high frequency communications, only few efforts have been carried out in order to scale successful antennas to lower frequency applications, mainly ISM (International Scientific and Medical) ranges [2]. In this sense, RFID applications appear as good example of low-frequency printed antennas. This is a particular case, because the antennas are normally designed as radiating coils due to the low range of utilization [3].

For long range and low-frequency applications, wired antennas (Yagi-Uda and related designs) are commonly recommended. They are cheap, robust, easy to install, and their integration with the associated electronics, within a radome, is usually, a straightforward task. Only the absolute size, in some cases, can be considered a handicap [4].

We propose to exploit the knowledge achieved with the design of $2.45 \mathrm{GHz}$ antennas in order to translate them to applications below this frequency. At frequencies below $2.45 \mathrm{GHz}$, the losses tangent of low-cost substrates allows their use with more than acceptable efficiency figures [2]. In this sense, emerging technologies like direct material printing open new possibilities in this field, leading to compact, cheap, and flexible designs, useful for this kind of applications [5]. In addition, novel designs can reduce the overall size of the antenna in order to make it useful for standard applications [6].

In order to demonstrate these asserts, in this paper, we describe several microstrip printed antennas for different below $-2.45 \mathrm{GHz}$ applications, making use of previous successful designs. For demonstrating our proposal, we describe in detail two different designs, for narrow band and for wider band applications. We firstly present a Yagi-like antenna that can be used in wireless sensor network deployments or even for terrestrial digital television broadcasting links. Then, we 


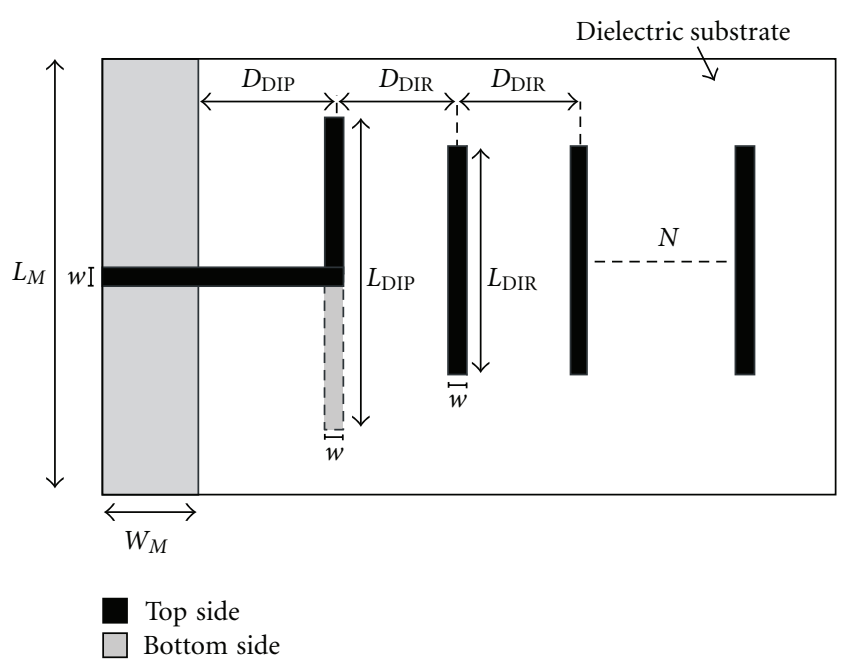

FIGURE 1: Yagi-like antenna scheme.

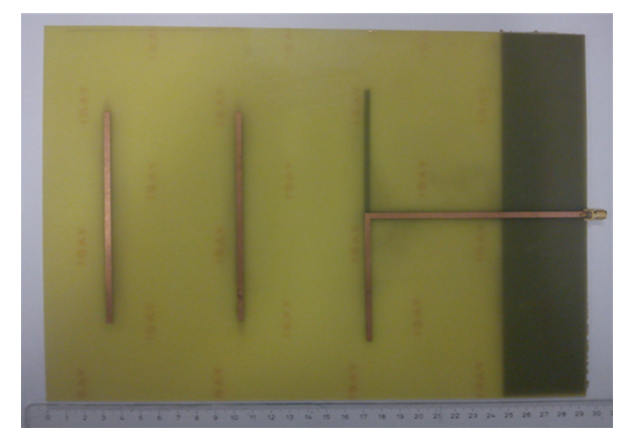

FIGURE 2: Fabricated prototype of the $868 \mathrm{MHz}$ Yagi-like antenna (ruler in $\mathrm{cm}$ ).

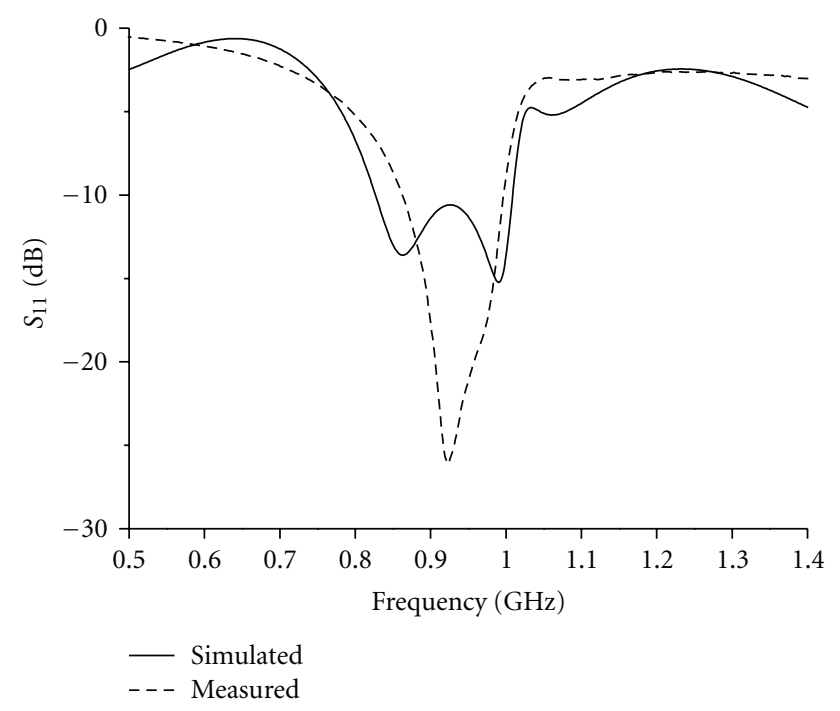

FIgURE 3: Simulated and measured return losses of the $868 \mathrm{MHz}$ Yagi-like antenna.

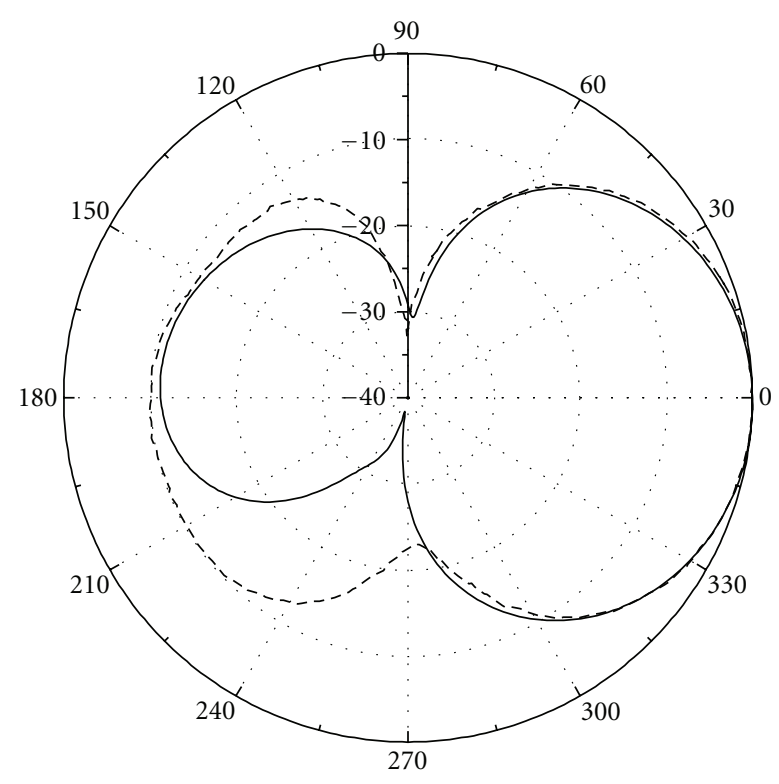

- Simulated

- - - Measured

(a) E plane



(b) H plane

Figure 4: Simulated and measured radiation patterns of the $868 \mathrm{MHz}$ Yagi-like antenna.

also describe a log-periodic printed antenna for wider band applications or parabolic antenna feeding. With all these designs we will demonstrate the potentiality of low-cost substrate printed antennas within these scenarios.

The more important parameters of the antenna were simulated and measured. For the calculated results an inhouse 3D-FDTD algorithm was used. The code was initially 
TABLE 1: Yagi-like antenna dimensions for $868 \mathrm{MHz}$.

\begin{tabular}{|c|c|c|c|}
\hline$L_{\mathrm{DIP}}=124.1 \mathrm{~mm}$ & $D_{\text {DIP }}=69.1 \mathrm{~mm}$ & $L_{\mathrm{DIR}}=101.5 \mathrm{~mm}$ & $D_{\text {DIR }}=69.1 \mathrm{~mm}$ \\
\hline$w=3.2 \mathrm{~mm}$ & $L_{M}=180 \mathrm{~mm}$ & $W_{M}=42.3 \mathrm{~mm}$ & \\
\hline
\end{tabular}

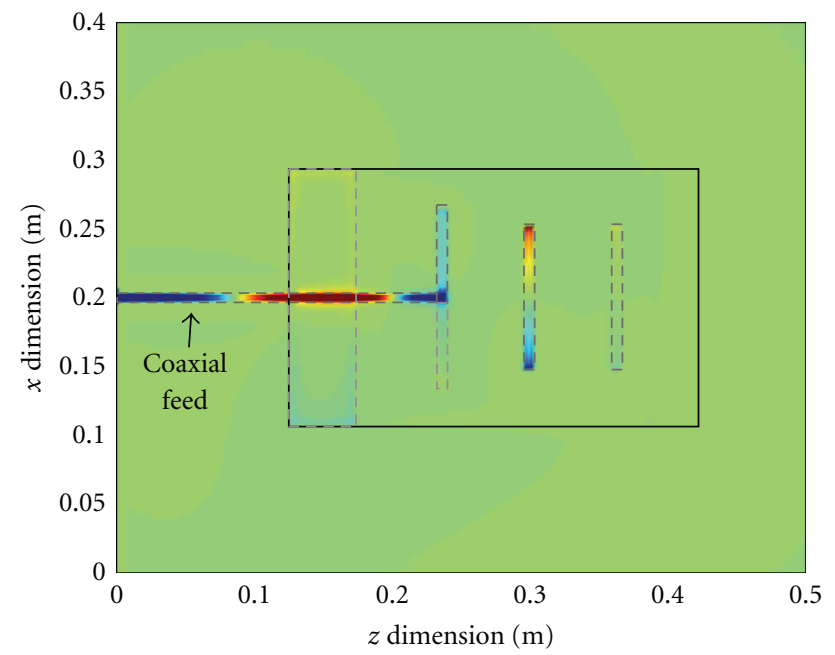

FIgURE 5: Field distribution of the $868 \mathrm{MHz}$ Yagi-like antenna.

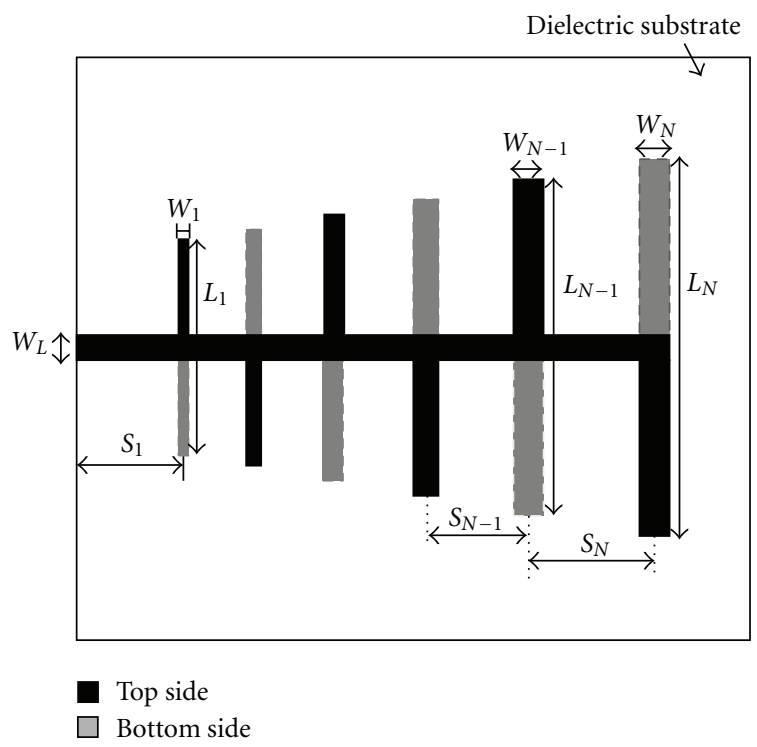

Figure 6: Log-periodic antenna scheme.

designed for radar antennas analysis [7] and then was adapted for electrical parameters calculations [8] and microstrip printed antenna modelling [9]. The measures were carried out with a vectorial network analyser within an anechoic chamber.

\section{Results}

The presented antennas are fabricated by making use of a standard low-cost FR4 substrate, typically used in printed

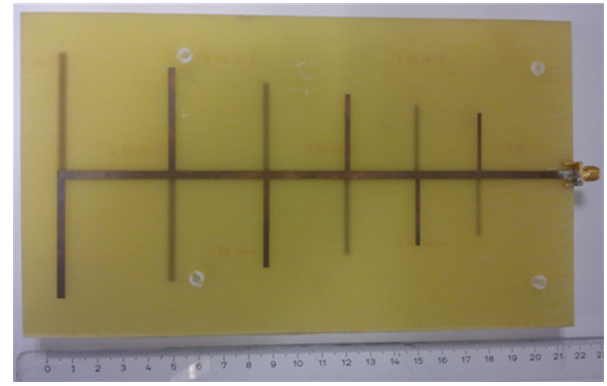

FIGURE 7: Fabricated prototype of the log-periodic antenna (ruler in $\mathrm{cm}$ ).

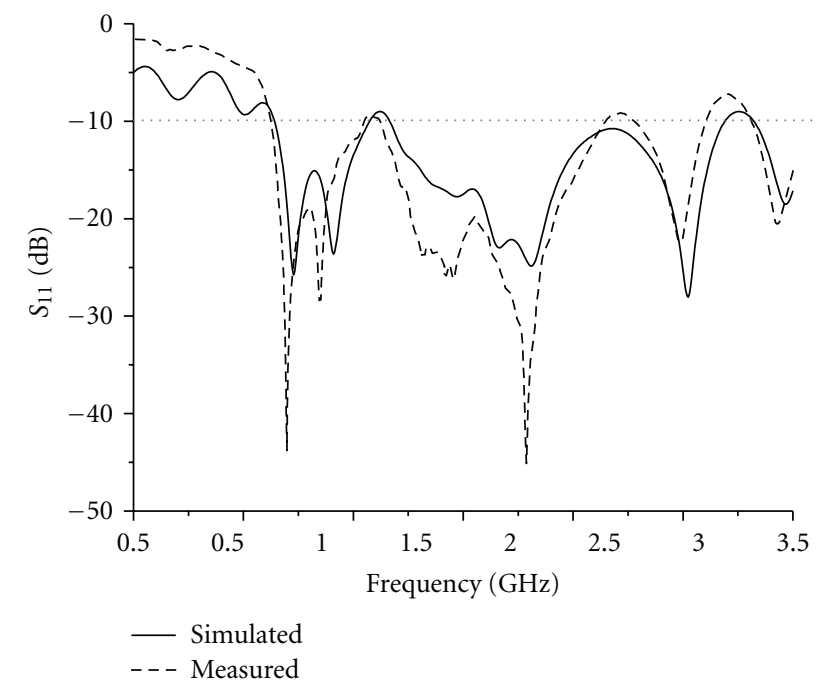

FIGURE 8: Simulated and measured return losses of the log-periodic antenna.

circuits designs, with a width $h=1.52 \mathrm{~mm}$ and relative dielectric constant of 3.9 at the used frequency range.

2.1. Yagi-Like Antenna. This antenna is proposed for open field wireless sensor networks applications at the free license $868 \mathrm{MHz}$ band. In a particular application [10], some weather stations are located in different and remote places in a wide region $\left(10 \times 10 \mathrm{~km}^{2}\right)$. For far end-node stations, standard directive Yagi-Uda antennas are normally used. Printed antennas are proposed as a good alternative for this kind of applications, because their low price and the possibility of integration with the nonmetallic box of the electric sensing devices.

The scheme of the Yagi-like antenna is shown in Figure 1. The antenna consists on a dipole with the arms located in both sides of the dielectric substrate and a number of director elements with the same dimensions. The dipole is fed by 


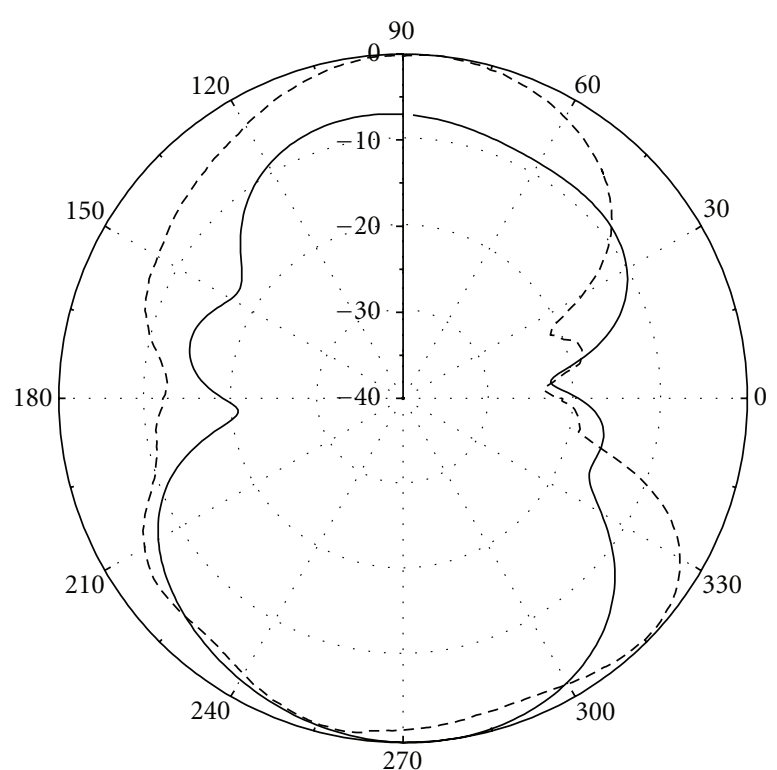

(a) E plane $1.4 \mathrm{GHz}$

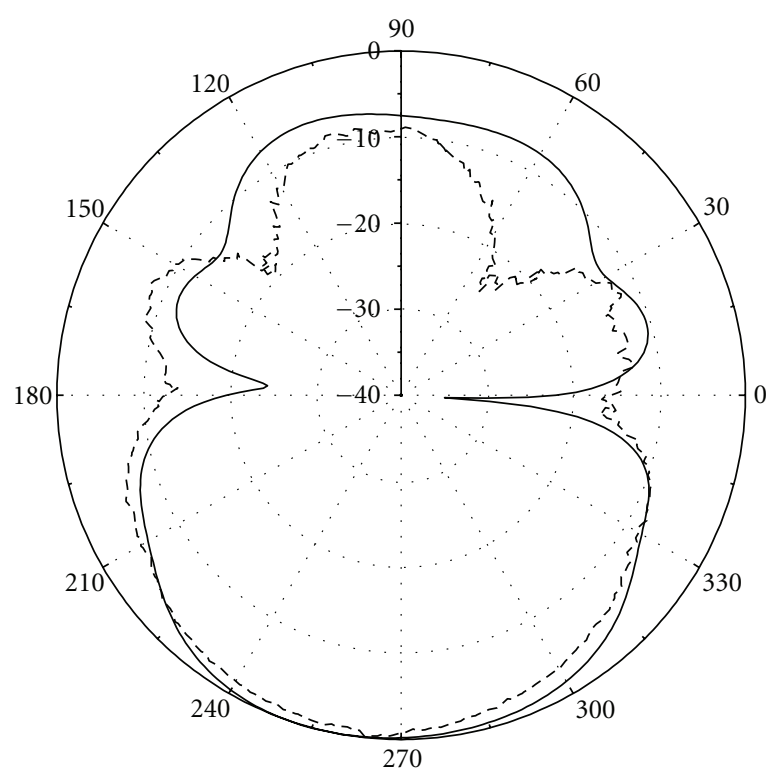

- Simulated
- - Measured

(c) E plane $2.2 \mathrm{GHz}$

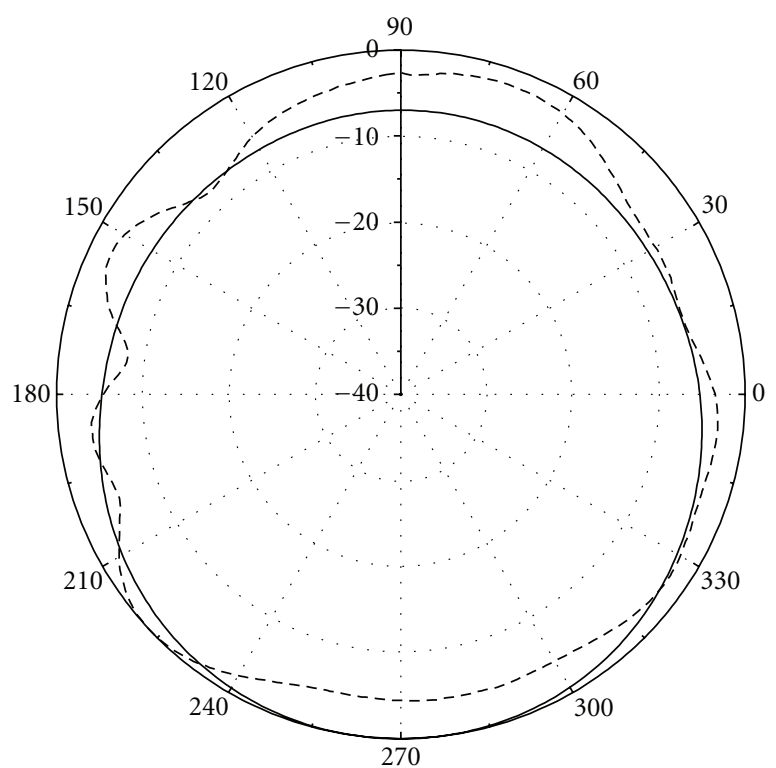

(b) $\mathrm{H}$ plane $1.4 \mathrm{GHz}$

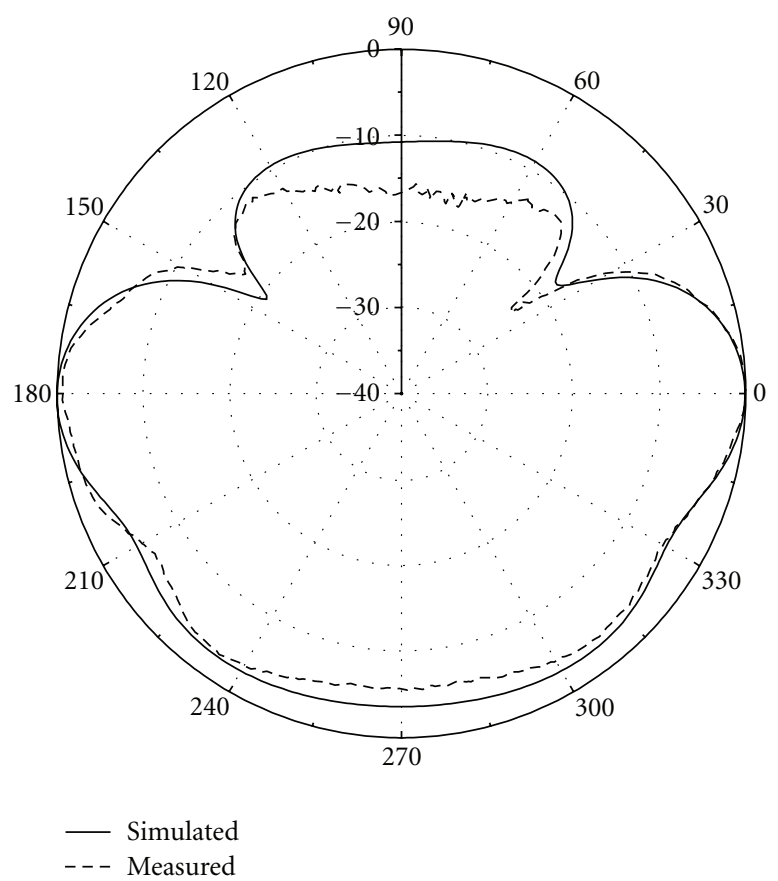

(d) H plane $2.2 \mathrm{GHz}$

FIgURE 9: Simulated and measured radiation patterns of the log-periodic antenna.

a strip line printed on both sides of the substrate. This scheme of the driver provides the necessary electrical phase to each arm of the dipole, without external elements, allowing a reduction of the final size of the antenna. At the bottom side of the dielectric substrate a truncated ground plane is located. This ground plane acts as reflector element of the antenna [11].

The dipole length is slightly smaller than $\lambda / 2$ at the work frequency and the other dimensions of the antenna are obtained by parametric simulations with our 3D-FDTD algorithm [12].

The Yagi-like printed antenna is designed for an $868 \mathrm{MHz}$ frequency work onto a piece of low-cost FR4 substrate. Due to final size of the Yagi-like antenna at this low frequency, only two director elements are considered. The optimized dimensions of the antenna are summarized in Table 1. In Figure 2 we show the fabricated prototype of the Yagi-like antenna. 


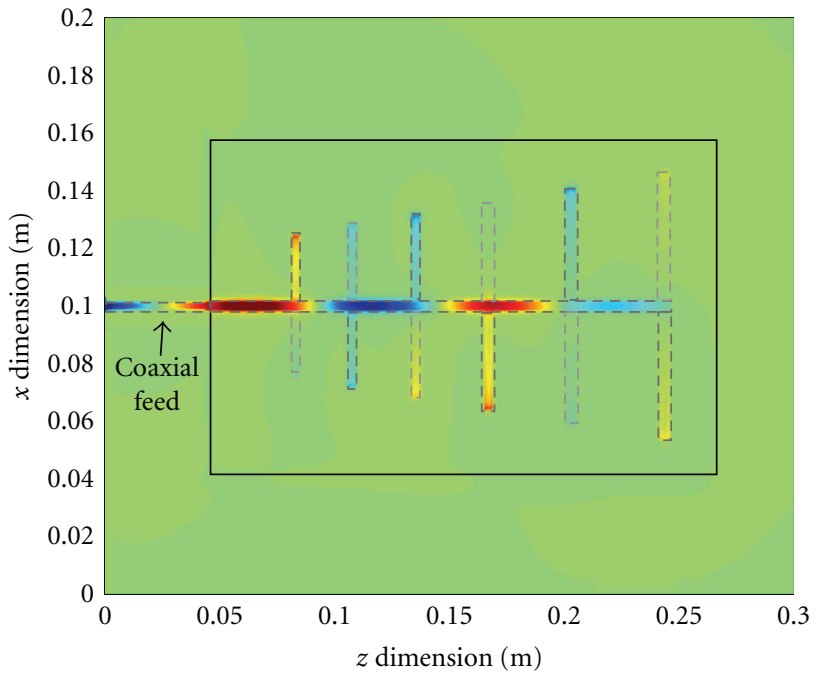

(a) $1.4 \mathrm{GHz}$

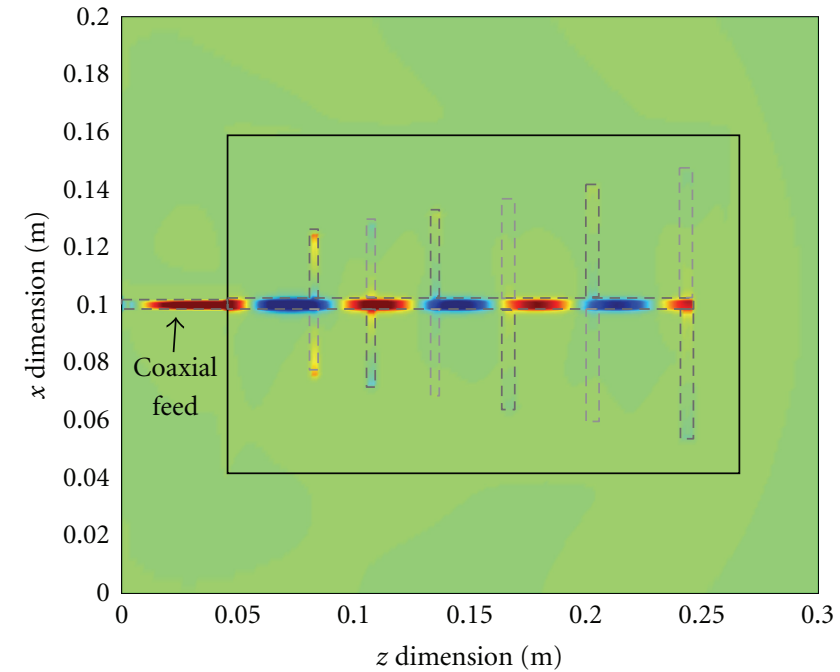

(b) $2.2 \mathrm{GHz}$

Figure 10: Field distribution of the log-periodic antenna.

TABle 2: Log-periodic antenna dimensions $(\tau=0.88)$.

\begin{tabular}{lcccc}
\hline$L_{1}=48.8 \mathrm{~mm}$ & $L_{2}=55.5 \mathrm{~mm}$ & $L_{3}=63 \mathrm{~mm}$ & $L_{4}=71.6 \mathrm{~mm}$ & $L_{5}=81.4 \mathrm{~mm}$ \\
$L_{6}=92.5 \mathrm{~mm}$ & $S_{1}=38.3 \mathrm{~mm}$ & $S_{2}=24.4 \mathrm{~mm}$ & $S_{3}=27.7 \mathrm{~mm}$ & $S_{4}=31.5 \mathrm{~mm}$ \\
$S_{5}=35.8 \mathrm{~mm}$ & $S_{6}=40.7 \mathrm{~mm}$ & $W_{1}=1.6 \mathrm{~mm}$ & $W_{2}=1.8 \mathrm{~mm}$ & $W_{3}=2.04 \mathrm{~mm}$ \\
$W_{4}=2.32 \mathrm{~mm}$ & $W_{5}=2.64 \mathrm{~mm}$ & $W_{6}=3 \mathrm{~mm}$ & $W_{L}=3 \mathrm{~mm}$ & \\
\hline
\end{tabular}

The measured and calculated return losses are presented in Figure 3. A good agreement between both results is obtained, with a measured bandwidth of $138 \mathrm{MHz}$, around $15 \%$ of the central frequency.

The measured and calculated normalized radiation patterns of the Yagi-like antenna for the principal planes at $868 \mathrm{MHz}$ are presented in Figure 4. As observed, the antenna displays a directive behaviour with a measured gain of $7 \mathrm{dBi}$. The estimated antenna efficiency was around $92 \%$.

In Figure 5 we show the normalized electric field distribution $E_{y}$ component in the middle point of the dielectric substrate at $868 \mathrm{MHz}$. It is well appreciated that the antenna is fed with the correct phase at the operation frequency.

2.2. Log-Periodic Antenna. In this paragraph we focus on a wider band design. The range of application of such antennas is well stated [13]. Our particular design includes the L-band and the standard Wi-Fi band, as an example of integrating both technologies.

The antenna scheme is shown in Figure 6. The antenna consists of a number of printed dipoles with the arms printed in both sides of the dielectric substrate alternatively. Shorter dipoles are located close to the feed point. A strip line printed on both sides of the substrate is used to feed all dipoles. This scheme provides the necessary phase distribution to all dipoles of the antenna. All dimensions of the antenna follow the

$$
\tau=\frac{L_{x-1}}{L_{x}}=\frac{S_{x-1}}{S_{x}}=\frac{W_{x-1}}{W_{x}}
$$

where $L_{x}$ is the length of the dipole " $x$ ", $W_{x}$ is the width of the dipole " $x$ " and $S_{x}$ is the separation between the dipole " $x$ ", and the dipole " $x-1$ ". The dipole length is associated with the work frequency, the dipole width with the dipole impedance and the separations between dipoles is associated with the coupling between neighbouring dipoles. The feed line width is adjusted for a $50 \Omega$ impedance at the feed point. The optimal behaviour of the log-periodic antenna is achieved when the periodic relationship between dimensions is $\tau=0.88$ [13].

The log-periodic antenna proposed consists of 6 dipoles, with the bigger dipole designed for a work frequency of $1.2 \mathrm{GHz}$ and the small dipole designed for $2.58 \mathrm{GHz}$. As dielectric substrate, a piece of low-cost FR4 substrate was used. The final dimensions, optimized with a parametric study carried out with the 3D-FDTD algorithm [12], are summarized in Table 2 . The fabricated prototype is show in Figure 7.

The measured and simulated return losses are presented in Figure 8, with a good agreement between both results within the whole frequency range studied. As observed, for VSWR $<2\left(S_{11}<10\right)$ two frequency bands are obtained. This dual behaviour instead of a wide-band feature is due to the electric coupling between dipoles and is typical in these logperiodic antennas when the number of dipoles increases [13]. The central frequency of the first frequency band is $1.34 \mathrm{GHz}$ (measured results) with a bandwidth of $430 \mathrm{MHz}$. The second frequency band is centred at $2.14 \mathrm{GHz}$ and the bandwidth is around $1 \mathrm{GHz}$. 
In Figure 9, we present the measured and simulated radiation patterns of the antenna at the central frequency of the two bands and for the principal planes. A slightly directive behaviour is observed, especially at the second frequency band, with the maximum of radiation towards the feed point. The measured gain was $4.8 \mathrm{dBi}$ for the central frequency of the first band and around $0 \mathrm{dBi}$ for $2.2 \mathrm{GHz}$.

Finally, the electric field distribution $E_{y}$ component in the middle point of the dielectric substrate is calculated from the time domain electric and magnetic fields. The results for the central frequency of both frequency bands of the logperiodic antenna are presented in Figure 10. The estimated antenna efficiency was about $90 \%$ for the low-frequency band and about $83 \%$ for the high-frequency band.

\section{Conclusions}

Microstrip printed technology can be used for the design of good performing antennas for frequencies below $2.45 \mathrm{GHz}$. Due to the lesser losses at lower frequencies, low cost substrates can be considered. In addition, for dipole based designs, the electromagnetic field mainly travels through the air. This fact helps to have good efficiencies and acceptable overall antenna sizes. This way, antennas for the proposed purposes can be fabricated in a DIN A4 standard sheet of common printed circuit board (PCB) such as FR4. Successful designs have been demonstrated for a Yagi-like antenna for wireless sensor network deployment (ISM band at $868 \mathrm{MHz}$ ) and a log-periodic dipole printed antenna for wide band applications. The efficiency in all cases was around 90\%, keeping good electrical $\left(S_{11}\right)$ and radiation parameters.

\section{References}

[1] C. I. Votis, P. Kostarakis, and A. A. Alexandridis, "Design, analysis, and measurements of an antenna structure for $2.4 \mathrm{GHz}$ wireless applications," International Journal of Antennas and Propagation, vol. 2010, Article ID 796154, 14 pages, 2010.

[2] E. Ávila-Navarro, J. A. Carrasco, and C. Reig, "Printed dipole antennas for personal communication systems," IETE Technical Review, vol. 27, no. 4, pp. 286-292, 2010.

[3] T. Björninen, S. Merilampi, L. Ukkonen, L. Sydänheimo, and P. Ruuskanen, "The effect of fabrication method on passive UHF RFID tag performance," International Journal of Antennas and Propagation, vol. 2009, Article ID 920947, 8 pages, 2009.

[4] H. Yagi, "Beam transmission of the ultra short waves," Proceedings IRE, vol. 16, pp. 715-741, 1928.

[5] A. K. Sowpati, V. K. Palukuru, V. Pynttäri, R. Mäkinen, M. V. Kartikeyan, and H. Jantunen, "Performance of printable antennas with different conductor thickness," Progress In Electromagnetics Research Letters, vol. 13, pp. 59-65, 2010.

[6] Y. Qian, W. R. Deal, N. Kaneda, and T. Itoh, "Microstrip-fed quasi-Yagi antenna with broadband characteristics," Electronics Letters, vol. 34, no. 23, pp. 2194-2196, 1998.

[7] C. Reig, E. A. Navarro, and V. Such, "FDTD analysis of an Esectoral horn excited by an opened microstrip," Microwave and Optical Technology Letters, vol. 13, no. 5, pp. 294-297, 1996.

[8] C. Reig, E. A. Navarro, and V. Such, "Calculation of the characteristic impedance of microstrips using a full-wave 2-D
FDTD scheme," Microwave and Optical Technology Letters, vol. 16, no. 1, pp. 58-60, 1997.

[9] E. Ávila-Navarro, A. Segarra-Martínez, J. A. Carrasco, and C. Reig, "A low-cost compact uniplanar Quasi-Yagi printed antenna," Microwave and Optical Technology Letters, vol. 50, no. 3, pp. 731-735, 2008.

[10] A. Cano, E. López-Baeza, J. L. Añón, C. Reig, and C. MillánScheiding, "Wireless sensor network for soil moisture applications," in International Conference on Sensor Technologies and Applications (SENSORCOMM '07), pp. 508-513, October 2007.

[11] E. Ávila-Navarro, J. A. Carrasco, and C. Reig, "Design of Yagilike printed antennas for wlan applications," Microwave and Optical Technology Letters, vol. 49, no. 9, pp. 2174-2178, 2007.

[12] E. Ávila-Navarro, J. A. Carrasco, and C. Reig, "Dual printed antenna for Wi-Fi applications," IEEE Antennas and Wireless Propagation Letters, vol. 8, Article ID 4967968, pp. 596-598, 2009.

[13] E. Ávila-Navarro, J. M. Blanes, J. A. Carrasco, C. Reig, and E. A. Navarro, "A new bi-faced log periodic printed antenna," Microwave and Optical Technology Letters, vol. 48, no. 2, pp. 402-405, 2006. 

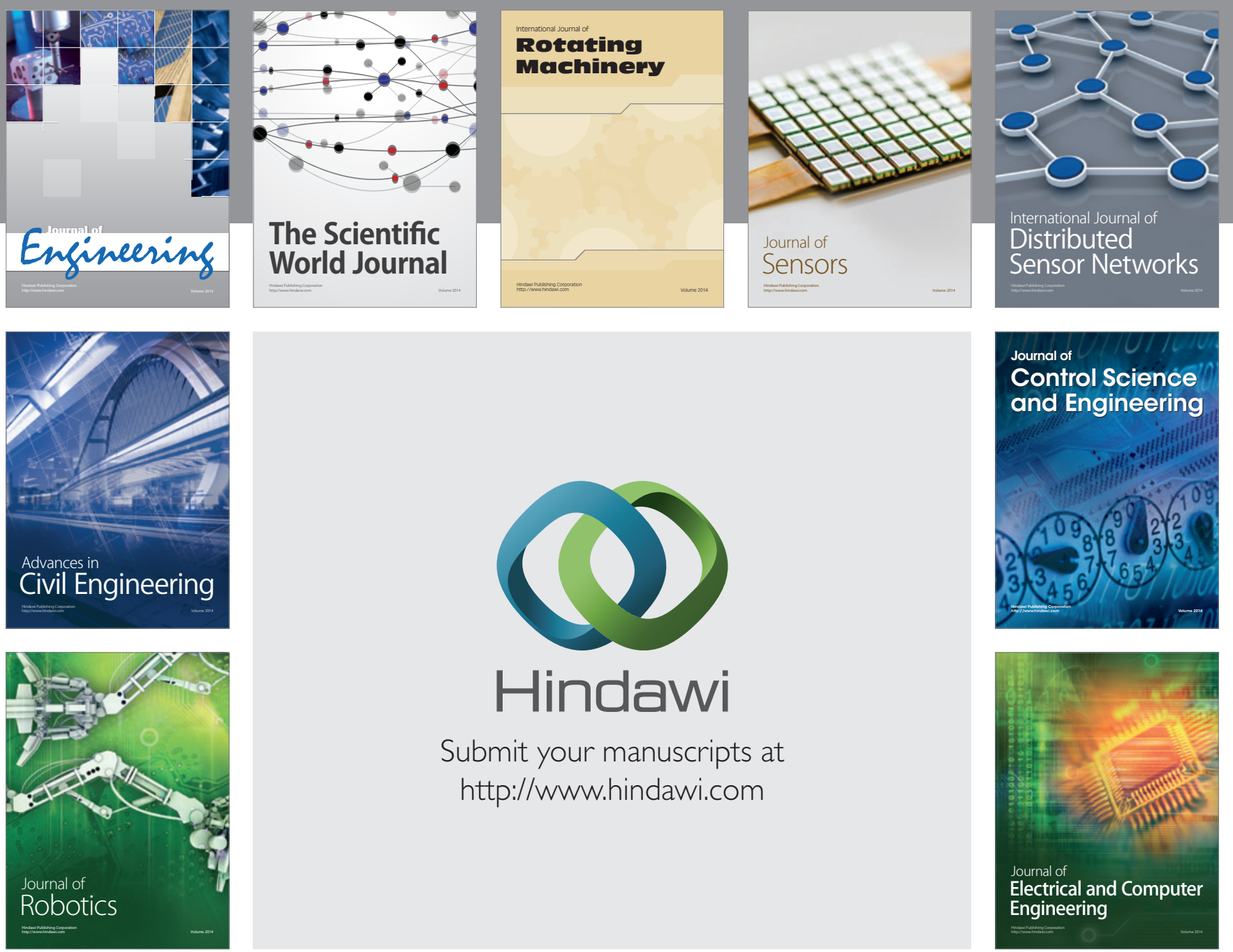

Submit your manuscripts at

http://www.hindawi.com
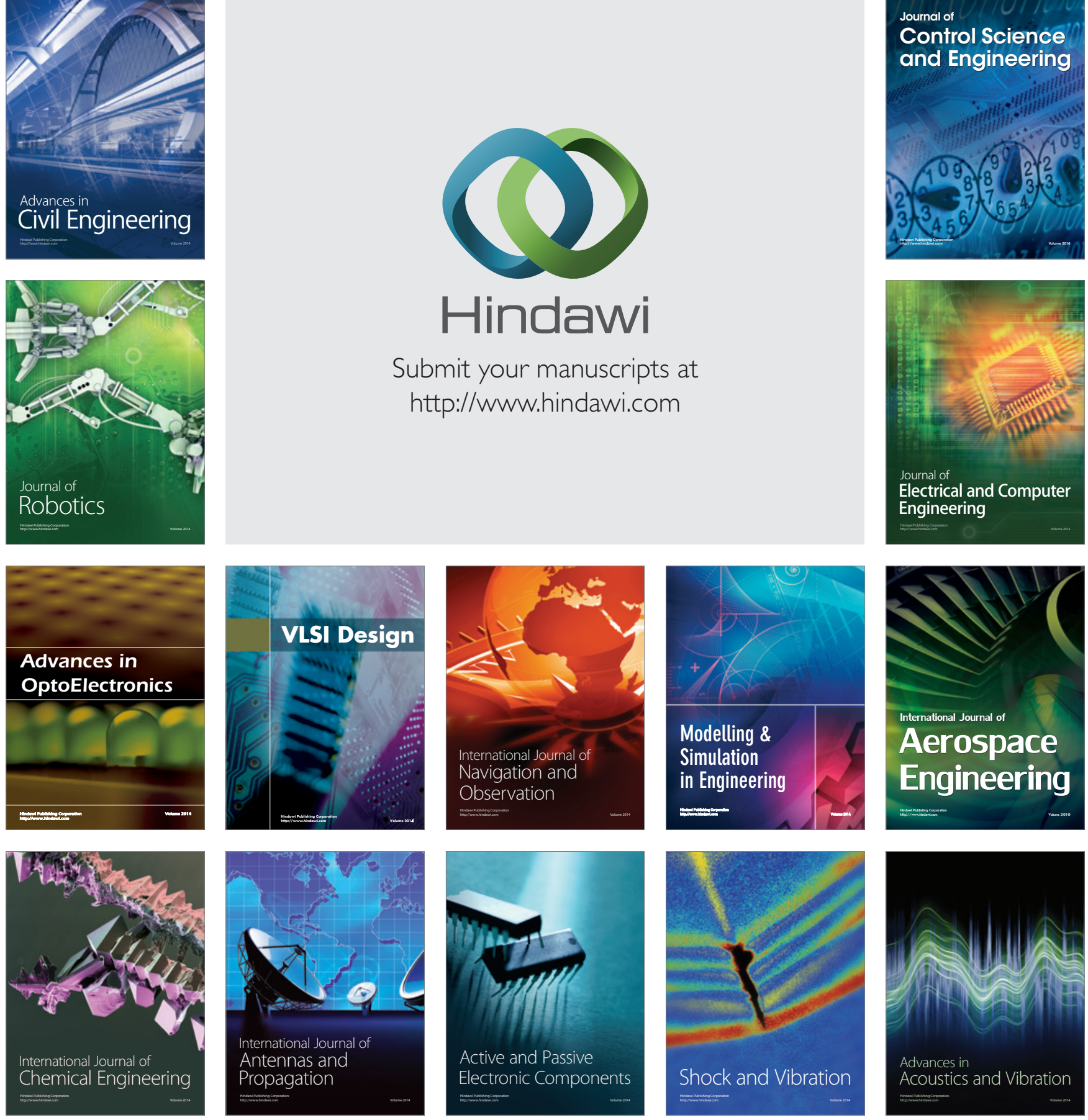